\title{
BB2 Joubert Denizaltı Formunun Sevk Noktasının Sayısal Olarak incelenmesi
}

\author{
Alpay Acar ${ }^{1}$, Yasemin Arıkan Özden ${ }^{2}$ \\ ${ }^{1}$ Gemi İnşaatı ve Gemi Makineleri Mühendisliği Bölümü, Deniz Harp Okulu, Milli Savunma Üniversitesi İstanbul, \\ Türkiye \\ ${ }^{2}$ Yıldız Teknik Üniversitesi, Gemi İnşaatı ve Denizcilik Fakültesi, Gemi İnşaatı ve Gemi Makineleri Mühendisliği \\ Bölümü, İstanbul, Türkiye \\ 1 (sorumlu yazar), aacar@dho.edu.tr, ORCID: 0000-0002-6254-8018 \\ ${ }^{2}$ yarikan@yildiz.edu.tr, 0000-0001-9909-0859
}

\section{ÖZET}

Günümüzde birçok donanma denizaltılara sahip durumdadır ve birçoğu denizaltılarını donanmaların bel kemiği olarak ifade etmektedir. Tarihte birincil harekât görevi deniz ticaret yollarını kesmek/kontrol etmek olan dizel elektrikli denizaltıların günümüzde en önemli görevleri fark edilmeden bilgi toplamak ve gerektiğinde su altı, su üstü, kara ve hava hedeflerine sürpriz harekât gerçekleştirebilmektir. Denizaltılar su üstüne çıktıklarında ve hatta gövdeleri su üstüne çıkmadan sadece şnorkel seyri yapmak için periskop derinliğine geldiklerinde dahi günümüzün yüksek teknolojik radar sistemleri sayesinde fark edilebilmekte ve görünmezliklerini yitirmektedirler. Denizaltıların seyirleri esnasında bataryalarını şarj ettikleri sürenin, denizaltıların su altında geçirdikleri süreye oranı, şnorkel seyir süresi oranı (indiscretion rate) olarak isimlendirilmektedir. Bu oranı azaltmak, denizaltıların görünmezliğinin bir ölçüsü olarak nitelendirilmektedir. Yeni tasarımlar ve teknolojiler geliştirilirken bu oranı aşağı çekmek ana tasarım hedefi olarak ele alınmaktadır. Denizaltıların su altı seyir sığalarını önemli ölçüde artıran havadan bağımsız sevk sistemleri modern denizaltıların şnorkel seyir süresi oranını aşağı çekmiş ve bu sistemlerle donatılmış günümüz denizaltısının harekât sahası, kahverengi sulardan mavi sulara kaymaktadır. Şnorkel seyir süresi oranına diğer bir önemli etken ise denizaltının hidrodinamik formu ve sevk verimliliğidir. Daha verimli bir forma sahip olan denizaltı su altında aynı sürat ve aynı enerji kapasitesi ile daha uzun süre seyir yapabilecek ve daha düşük bir şnorkel seyir süresi oranına sahip olacaktır. Günümüzde hesaplamalı akışkanlar dinamiği tasarımcılar tarafından etkin bir araç olarak kullanılmakta ve denizaltıyı istenilen servis süratlerinde daha verimli sevk edebilecek hidrodinamik formların ve bu formları itecek pervanelerin gerek yüksek verimle gerekse düşük akustik ize sahip olarak tasarlanabilmesine olanak tanımaktadır. Bu çalışmada, açık literatürde yapılan çalışmalarda son yıllarda sıklıkla tercih edilen Joubert BB2 denizaltı formunun direnci hesaplamalı akışkanlar dinamiği yöntemleri ile hesaplanmış ve denizaltının sevkinde kullanılan pervanenin geminin servis hızında gemiyi itmek için gereken devir sayısı bilgilerine ulaşılmıştır. Sevk noktasının tayini ile denizaltı formuna has Taylor iz katsayısı, itme azalması, tekne verimi, bağıl dönme verimi ve bunlara bağlı sevk verimi hesap edilmiştir.

Anahtar kelimeler: Denizaltı, Taylor iz katsayısı, itme azalması, tekne verimi, sevk verimi, sevk noktası, hesaplamalı akışkanlar dinamiği (HAD)

Makale geçmişi: Geliş 08/05/2021 - Kabul 02/12/2021

https://doi.org/10.54926/gdt.934890 


\title{
Numerical Investigation of Self Propulsion of BB2 Joubert Submarine Form
}

\author{
Alpay Acar ${ }^{1}$, Yasemin Arıkan Özden ${ }^{2}$ \\ ${ }^{1}$ Department of Naval Architecture and Marine Engineering, Turkish Naval Academy National Defence \\ University, İstanbul, Türkiye \\ ${ }^{2}$ Faculty of Naval Architecture and Maritime, Naval Architecture and Marine Engineering Yıldız Technical \\ University, İstanbul, Türkiye \\ ${ }^{1}$ (corresponding author), aacar@dho.edu.tr, ORCID: 0000-0002-6254-8018 \\ ${ }^{2}$ yarikan@yildiz.edu.tr, 0000-0001-9909-0859
}

\begin{abstract}
Nowadays many Navies have submarines and refer them as the backbone of their Navies. The most important task of diesel-electric submarines, whose primary operational task in history was to intercept / control maritime trade routes, is to collect information without being noticed and to perform surprise operations against underwater, land and air targets when necessary. Submarines can be noticed and lose their invisibility thanks to today's high-tech radar systems when they come to the surface of the water and even when they reach periscope depth to go snorkeling without their hulls rising above the water. The ratio of the time submarines charges their batteries during their cruise to the time the submarines spend under water is called indiscretion rate. Reducing this rate is considered as a measure of the invisibility of submarines. While developing new designs and technologies, reducing this rate is considered as the main design goal. Air-independent propulsion systems, which significantly increase the underwater sailing range of submarines, have lowered the rate of snorkeling time of modern submarines, and the operation area of today's submarine equipped with these systems shifts from brown waters to blue waters. Another important factor in the rate of snorkeling cruising time is the hydrodynamic form and the propulsive efficiency of the submarine. The submarine, which has a more efficient form, will be able to cruise for a longer time with the same speed and same energy capacity underwater and will have a lower indiscretion rate. Nowadays, computational fluid dynamics is used by designers as an effective tool and enables the design of hydrodynamic forms that can drive the submarine more efficiently at desired service speeds and the propellers that will push these forms with both high efficiency and low acoustic trace. In this study, the self-propulsion characteristics of the Joubert BB2 submarine form, which has been frequently preferred in recent years in the studies conducted in the open literature, was calculated with computational fluid dynamics methods and the speed of the propeller used in the propulsion of the submarine was obtained to propel the ship at the service speed of the submarine. With the determination of the self-propulsion point, the Taylor wake fraction, thrust deduction, hull efficiency, relative rotative efficiency and propulsive efficiency were calculated and compared with open literature.
\end{abstract}

Keywords: Submarine, self-propulsion point, Taylor wake fraction, thrust deduction, hull efficiency, computational fluid dynamics (CFD) 


\section{Giriş}

Denizaltılara ait form, pervane geometrileri ve performans değerleri genellikle askeri gizli bilgiler olduğundan denizaltılar alanında yapılacak akademik çalışmaların doğrulanabilmesi amacı ile Amerika Birleşik Devletleri, DARPA (Defence Advanced Research Projects Agency) Suboff projesini başlatmıştır. Proje kapsamında farklı konfigürasyonlarda jenerik denizaltı formları oluşturulmuş ve bu formların direnç ve manevra değerleri deneysel yöntemlerle elde edilerek açık literatüre sunulmuştur (Groves vd., 1989; Huang vd., 1989; Crook, 1990; Roddy, 1990; Liu ve Huang, 1998). Günümüzde birçok araştırmacı bu formları kullanarak denizaltılar alanında sayısal ve deneysel çalışmalarını doğrulayabilmektedir.

Hesaplamalı akışkanlar dinamiği yöntemleri kullanılarak DARPA Suboff denizaltı formu ile yapılmış birçok çalışma bulunmaktadır. Sevk performansına yönelik çalışmalarda denizaltı modeli genellikle INSEAN (Italian Ship Model Basin) tarafından tasarlanan E1619 pervanesi (Di Fellice vd., 2009) ile birlikte kullanıımıştır. Alin vd. (2010) doğrusal hareketteki DARPA Suboff denizaltısının etrafındaki akımı DES ve LES yöntemleri ile incelemişler ve yine 2010 'da denizaltı-pervane etkileşimini LES yöntemine dayanan bir hesap metodolojisi ile hesaplamışlardır (Alin vd., 2010). Liefvendahl ve Troeng (2011) denizaltı pervanesindeki çevrimsel pervane yükünü LES yöntemi ile incelemişlerdir. Daha sonra Chase ve Carrica (2013), E1619 pervanesi ile sevk edilen DARPA Suboff jenerik modelini farklı çözüm ağı yoğunluklarında CFD Ship-lowa V4.5 ile analizlerini gerçekleştirmişlerdir. Çalışmalarında pervane açık su karakteristiklerini farklı ağ yoğunluklarında ve ilerleme sayılarında elde etmişler ve daha önce INSEAN tarafından sunulan deney sonuçları ile karşılaştırmışlardır. Ağ yoğunluğunun itme ve tork üzerindeki etkisinin zayıf ancak pervane gerisi iz üzerinde etkili olduğunu göstermişlerdir. Daha sonra tek bir ilerleme sayısında da RANS, DES, DDES ve türbülans modeli kullanmadan pervane açık su karakteristiklerini incelemişlerdir. RANS'ın izi dağıttığını ve türbülans modeli kullanmamanın ise pervane uçlarındaki girdapları fiziksel olarak kararsız bir hale soktuğunu göstermişlerdir. Daha sonra pervaneli denizaltının sevk analizlerini gerçekleştirip sevk noktasını sunmuşlardır. Özden vd. (2016), E1619 ile sevk edilen DARPA Suboff denizaltısının sevk noktasında ayrıklaştırılmış pervane ve nominal iz gerisinde tanımlanmış pervane olmak üzere iki durumda pervane kaynaklı gürültü tahminini gerçekleştirmişlerdir. Özden ve Çelik (2017), DARPA Suboff denizaltı modelinin sevk verimini hesaplamalı akışkanlar dinamiği yöntemleri ile farkıı kıç koniklik açıları için incelemişlerdir. Sezen vd. (2018) çalışmalarında E1619 pervaneli DARPA Suboff denizaltısının farklı hızlardaki sevk noktalarını aktüatör disk ve ayrıklaştırıımış pervane olmak üzere iki farklı yöntem ile hesaplamışlardır. Kınacı vd. (2018) çalışmalarında, DARPA Suboff, denizaltısı ile KCS ve DTC gemilerinin sevk analizlerini gerçekleştirmişlerdir. E1619 pervanesi ile sevk edilen DARPA Suboff denizaltısına ait bir sevk deneyi sonucu bulunmadığından sayısal olarak elde edilen sonuçların deneysel veriler ile karşılaştırılması mümkün olmamıştır. Özden vd. (2019), E1619 pervanesi ile sevk edilen DARPA Suboff denizaltısına ait sevk noktasını ITÜ Ata Nutku Model Deneyi Laboratuvarı'nda gerçekleştirdikleri deneyler ile belirleyerek açık literatüre sunmuşlardır. Sezen vd. (2021) yaptıkları çalışmada, DARPA Suboff denizaltısını üç farklı ölçekte inceleyerek ITTC 1978 güç tahmin yöntemini kullanarak tam ölçek için yapılan analizler ile sonuçlarını karşılaştırmışlardır.

Denizaltı sevk performansı ve manevrası hesapları için kullanılan bir diğer jenerik form ise Joubert denizaltı formudur. Joubert denizaltısı ilk olarak Avustralya Savunma Bilimleri ve Teknolojileri Organizasyonu'nun (DSTO) sponsorluğunda Joubert'in gerçekleştirdiği çalışmalar ile geliştirilmiştir (Joubert, 2004; Joubert, 2006). DSTO, bu geometrinin ölçekli bir modeliyle (Quick ve Woodyat, 2014) birçok rüzgâr tüneli deneyi yapmış ve daha sonra ortak bir uluslararası uygulamada (Toxopeus, 2013) denizaltı "BB1" adı altında kullanılmıştır. Geometriyi daha gerçekçi hale getirmek ve stabiliteyi 
arttırmak için MARIN (Maritime Research Institute Netherlands), yelken ve kuyruk düzlemlerinde (Toxopeus vd., 2017) değişiklikler yapmış ve revize edilmiş denizaltı geometrisini "BB2" olarak adlandırmıştır. BB2 geometrisi, MARIN tarafından ".3dm", ".igs" veya ".stp" formatlarında kullanıma sunulmaktadır.

BB2 Joubert denizaltısının sevk noktasını ve manevra karakteristiklerini Carrica vd. (2016) çalışmalarında, deneysel olarak ve üç farklı sayısal kod ile çözmüşlerdir. Takip modlu deney sistemi ile MARIN'de gerçekleştirilen deneyler satıha yakın ve dalmış durumda sevk deneylerini, dönme dairesi, zig zag manevra deneylerini, satıha çıkma ve crashback deneylerini kapsamaktadır. Sayısal çözümlerde kullanılan kodlar ReFRESCO, ReFRESCO/PROCAL ve REX paket yazılımlarıdır. RANS denklemleri ReFRESCO'da sıkıştırılamaz akışkan kabulü ile sonlu hacimler yöntemi ile ReFRESCO/PROCAL'da viskozitesiz akışkan kabulü ile aktuatör disk yaklaşımı ve sınır elemanlar yöntemi ile çözülmektedir. REX ise $k-\varepsilon, k$ - $\omega$ türbülans modelleri ile hibrit RANS/LES modellerini DES, DDES formunda çözmektedir. Deneylerden elde ettikleri verileri sayısal yöntemler ile elde ettikleri sonuçlar ile karşılaştırmışlardır. Sevk karakteristikleri için sonuçları \%5 sapma ile tahmin edebilmişlerdir. Carrica vd. (2019) bir başka çalışmada, BB2 denizaltısının satıha yakın seyir durumunda sakin ve dalgalı suda sevk noktasındaki performansını analiz etmişlerdir. Bu çalışmalarında, satıha yakın seyir durumunda form üzerine etki eden dalıp çıkma kuvveti ve baş kıç vurma moment değerleri $-6.9 \mathrm{~m}$ ile $40 \mathrm{~m}$ dalış derinliklerinde, deniz durumu 2 ile 7 arasında incelenmiştir. Satıha yakın seyir durumunda dalıp çıkma ve baş kıç vurma momentlerinde belirgin artışlar görülmüş ve pervanenin ihtiyaç duyduğu itme kuvvetinin artarak sevk veriminin düştüğü tespit edilmiştir.

Skejic ve Greve (2017), DARPA ve BB2 denizaltılarını periskop derinliğinde iken sakin ve düzenli dalgalı durumlarda direncini incelemişlerdir. Sakin suya göre dalgalı durumda her iki denizaltı için de direncin arttığı görülmüştür. BB2 denizaltısının formu itibari ile DARPA Suboff denizaltısına göre her iki durumda da daha az direnç oluşturduğunu göstermişlerdir.

Bir geminin sevk performansının sayısal yöntemler ile güvenilir ve doğru bir şekilde tahmin edilmesi günümüzde hala üzerinde çalışmalar yapılan bir araştırma konusudur. Bu çalışmanın amacı BB2 Joubert denizaltı formunun model ölçeğinde hesaplamalı akışkanlar dinamiği analizlerini yaparak tam ölçek için sevk performansının tahminlerinin yapılması ve daha önce literatürde verilmiş olan deneysel ve sayısal veriler ile karşılaştııılmasıdır.

\section{Geometriler}

\subsection{S7371R Pervanesi}

Bu çalışmada MARIN (Overpelt vd.,2015) (Maritime Research Institute Netherlands) tarafından paylaşılan S7371R pervanesi kullanılmıştır. S7173R pervanesi eğikliği yüksek altı kanatı bir denizaltı pervanesidir (Şekil 1). Pervanenin açık su deneyleri MARIN tarafından yapılmıştır. Pontarelli vd. (2017) tarafından pervanenin açık su pervane eğrisi sunulmuştur. Pervane özellikleri Tablo 1'de verilmektedir.

\subsection{BB2 Joubert Denizaltı Modeli}

Bu çalışmada denizaltı modeli olarak açık literatürde MARIN tarafından paylaşılan BB2 Joubert denizaltı formu kullanılmıştır (Şekil 2 ve Tablo 2). M9466 numarası ile üretilen bu model yine MARIN tarafından üretilen S7371R pervanesi ile 18.348 oranıyla küçültülerek deneyleri MARIN tarafından tatlı suda yapılmıştır. Bu deneylerde manevra testleri ve sevk deneyleri yürütülmüştür (Overpelt vd., 2015). 
ISSN: 1300-1973, e-ISSN: 2651-530X, Dergi ana sayfası: http://www.gmoshipmar.org/
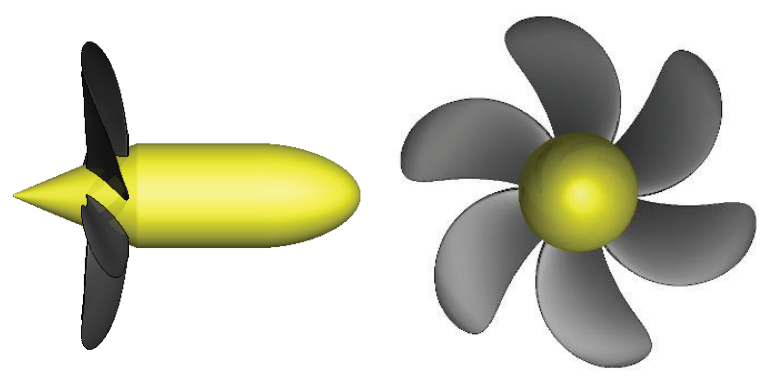

Şekil 1. MARIN S7371R Model Pervanesi

Tablo 1. S7371R Pervanesi Boyutları

\begin{tabular}{|c|c|c|c|}
\hline & & Gerçek & Model \\
\hline Pervane Kanat Sayısı & Z & 6 & 6 \\
\hline Çap $(m)$ & $\mathrm{D}$ & 5 & 0.273 \\
\hline Göbek Çap Oranı & $\mathrm{H} / \mathrm{D}$ & 0.2056 & 0.2056 \\
\hline $0.75 R^{\prime}$ de Kord Uzunluğu $(\mathrm{m})$ & $\mathrm{C}_{0.75}$ & 1.464 & - \\
\hline Kanat açıım alanı oranı & $\mathrm{A}_{\mathrm{E}} / \mathrm{A}_{0}$ & 0.00335 & 0.00335 \\
\hline
\end{tabular}
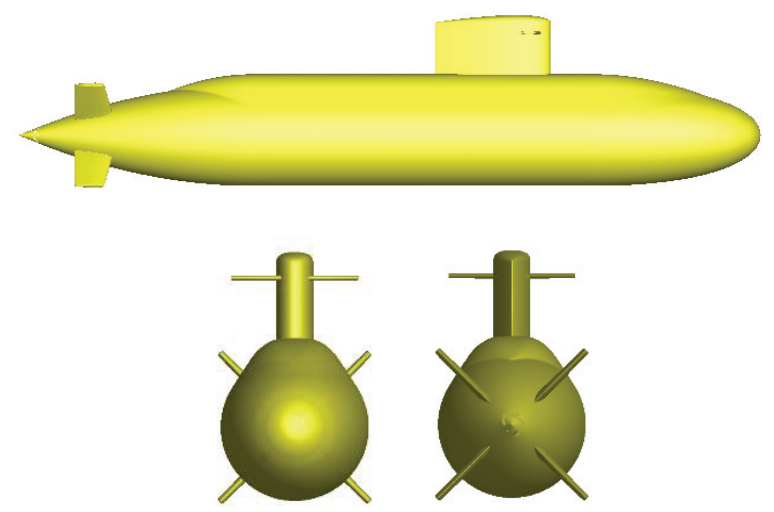

Şekil 2. BB2 Joubert Denizaltısı

Tablo 2. BB2 Joubert denizaltısı ana boyutları

\begin{tabular}{|l|l|l|l|}
\hline$\lambda=18.348$ & & Gerçek Denizaltı & Model Denizaltı \\
\hline Kaideler Arası Boy & LPp & $70.2 \mathrm{~m}$ & $3.826 \mathrm{~m}$ \\
\hline Genişlik & B & $9.6 \mathrm{~m}$ & $0.5235 \mathrm{~m}$ \\
\hline Derinlik & D & $10.6 \mathrm{~m}$ & $0.5781 \mathrm{~m}$ \\
\hline Derinlik (Yelken dahil) & $\mathrm{D}_{\text {sail }}$ & $16.2 \mathrm{~m}$ & $0.8835 \mathrm{~m}$ \\
\hline Blok Katsayısı & $\mathrm{C}_{\mathrm{b}}$ & 0.85 & 0.85 \\
\hline Deplasman Hacmi & $\nabla$ & $4358.2 \mathrm{~m}^{3}$ & $0.7056 \mathrm{~m}^{3}$ \\
\hline Islak Alan & $\mathrm{S}_{\text {WS }}$ & $2146.4 \mathrm{~m}^{2}$ & $6.3756 \mathrm{~m}^{2}$ \\
\hline
\end{tabular}

\section{Sayısal Yöntem}

Çözüm ağları yapılandırılmamış, T-REX elemanlardan Pointwise programında oluşturulmuştur. Yüzeyden boyutsuz uzaklık olarak $\mathrm{y}^{+}=50$ olarak seçilmiştir. Çözüm ağı bağımsızlığı incelemesi için orta 
sıklıktaki çözüm ağı trilineer interpolasyon şemasına göre $\sqrt{2}$ oranı kullanılarak sıklaştırılıp seyreltilerek üç farklı yoğunluk için çözüm ağları elde edilmiştir. Hesaplamalı akışkanlar dinamiği analizleri sonlu hacimler yöntemini kullanan ANSYS FLUENT 14.0 paket yazılımı ile gerçekleştirilmiştir. Analizlerde türbülans modeli k- $\omega$ SST (Shear Stress Transpot) ve çözüm şeması SIMPLE (Semi Implicit Methods for Pressure Linked Equations) olarak seçilmiştir. Ayrıklaştırma yöntemi olarak Green-Gauss node based seçilmiştir. Zamandan bağımsız olarak gerçekleştirilen analizlerde seçilen diğer unsurlar Tablo 3'te verilmiştir.

Tablo 3. Hesaplamalarda kullanılan çözüm şemaları ve türbülans sınır şartları

\begin{tabular}{|l|c|c|c|}
\hline & $\begin{array}{c}\text { S7371R } \\
\text { Pervanesi }\end{array}$ & BB2 Joubert & $\begin{array}{c}\text { Pervaneli BB2 } \\
\text { Joubert }\end{array}$ \\
\hline Basınç ayrıklaştırması & İkinci mertebe & İkinci mertebe & İkinci mertebe \\
\hline $\begin{array}{l}\text { Momentum } \\
\text { denklemleri }\end{array}$ & QUICK & İkinci mertebe & İkinci mertebe \\
\hline $\begin{array}{l}\text { Türbülans kinetik } \\
\text { enerjisi }\end{array}$ & QUICK & İkinci mertebe & QUICK \\
\hline $\begin{array}{l}\text { Spesifik yayılma oranı } \\
\text { Türbülans Yoğunluğu }\end{array}$ & QUICK & İkinci mertebe & QUICK \\
\hline $\begin{array}{l}\text { Türbülans viskozite } \\
\text { oranı }\end{array}$ & 5 & 2 & 2 \\
\hline
\end{tabular}

\subsection{S7371R Pervanesi Açık Su Karakteristikleri ve Pervane Gerisi İzin HAD ile Tahmini}

S7371 pervanesinin model ölçeğinde analizleri yapılırken, çözüm hacmi 16.5xD uzunluğunda ve 7.3xD çapında büyük silindir bir hacim olarak oluşturulmuştur. Ayrıca pervaneye dönme hareketi vermek için pervane 3.3xD uzunluğunda ve 1.5xD çapında daha küçük bir silindir içine yerleştirilmiştir. Akış silindire akışın girdiği yüzeyde hız girişi olarak tanımlanmıştır. Akışın çıktığı yüzey basınç çıkışı olarak seçilmiş ve basınç değişimi sıfır olarak belirlenmiştir. Çözüm ağını oluşturan silindirin dış kabuğu simetri olarak seçilmiştir. Pervanenin bulunduğu küçük silindirin tüm yüzeyleri ise ara yüzey olarak tanımlanmıştır. Pervane ve pervane göbeği yüzeyleri duvar olarak seçilmiştir (Şekil 3). Dönme hareketi Moving Reference Frame (MRF) yöntemi ile uygulanmıştır Farklı pervane ilerleme katsayılarındaki itme katsayısı $\left(\mathrm{K}_{\mathrm{T}}\right)$, tork katsayısı $\left(\mathrm{K}_{\mathrm{Q}}\right)$ ve açı ı su pervane verimi $\left(\eta_{\mathrm{o}}\right)$ gibi pervane karakteristik değerleri, farkı çözüm ağı yoğunlukları için devir sayısı (n) $15 \mathrm{~d} / \mathrm{s}$ sabit tutulup, akış hızı $\left(\mathrm{V}_{\mathrm{A}}\right)$ değiştirilerek hesaplanmıştır. Sonuçlar, Pontarelli vd. (2017) tarafından sunulan deney sonuçları ile karşılaştırıımış bir şekilde Tablo 4'te ve pervane açık su grafiği olarak Şekil 4'te sunulmuştur. Ayrıca analiz için pervane gerisi iz durumu Şekil 5'te paylaşılmıştır.

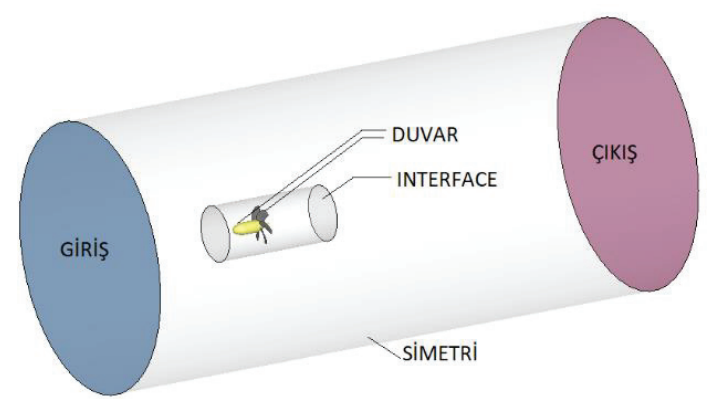

Şekil 3. S7371R Pervanesi çözüm hacmi 
Üç farklı ağ yoğunluğunda gerçekleştirilen analiz değerlerinin, deney değerlerinden sapma miktarları Tablo 4'te görülmektedir. Tablo 4'teki yüzdelik sapma miktarları değerlendirildiğinde pervane için sık ağ yoğunluğunun deneye en yakın sonucu verdiği görülmüş ve sevk analizi için $\$ 7371$ pervanesinde sık ağ yoğunluğu kullanılmıştır.

Tablo 4. Farklı çözüm ağı yoğunlukları için $\mathrm{J}=0.3^{\prime}$ te $\left(\mathrm{J}=\mathrm{V}_{\mathrm{A}} / \mathrm{nD}\right)$ pervane açık su performans karakteristikleri

\begin{tabular}{|l|c|c|c|c|c|c|c|c|}
\hline \multirow{2}{*}{$J=0.3$ için } & \multicolumn{2}{|c|}{ Hacim Hücre Sayısı } & \multicolumn{2}{|c|}{ CFD Analiz Değerleri } & \multicolumn{2}{|c|}{$\begin{array}{c}\text { Deney Sonuçları } \\
\text { (Pontarelli vd., } \\
\text { 2017) }\end{array}$} & \multicolumn{2}{|c|}{$\begin{array}{c}\text { Sapma Miktarı } \\
\text { (\%) }\end{array}$} \\
\cline { 2 - 4 } & $\begin{array}{c}\text { Küçük } \\
\text { Silindir }\end{array}$ & $\begin{array}{c}\text { Büyük } \\
\text { Silindir }\end{array}$ & KT & Ka & KT & Ka & $K_{T}$ & Ka \\
\hline $\begin{array}{l}\text { Seyrek Ağ } \\
\text { Yoğunluğu }\end{array}$ & $2.04 \times 10^{6}$ & $0.14 \times 10^{6}$ & 0.3868 & 0.0594 & & & 3.401 & 7.489 \\
\hline $\begin{array}{l}\text { Orta Ağ } \\
\text { Yoğunluğu }\end{array}$ & $3.5 \times 10^{6}$ & $0.28 \times 10^{6}$ & 0.3959 & 0.05886 & 0.374 & 0.055 & 5.830 & 6.516 \\
\hline $\begin{array}{l}\text { Sık Ağ } \\
\text { Yoğunluğu }\end{array}$ & $8.3 \times 10^{6}$ & $0.82 \times 10^{6}$ & 0.3881 & 0.0572 & & & 3.747 & 3.477 \\
\hline
\end{tabular}

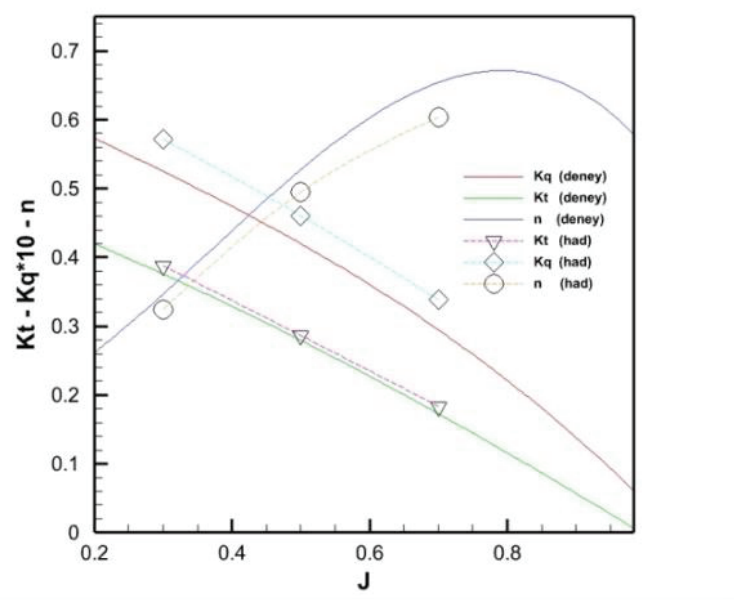

Şekil 4. S7371R Pervanesi Açık Su Pervane Değerleri ve Sık Çözüm Ağı Durumu

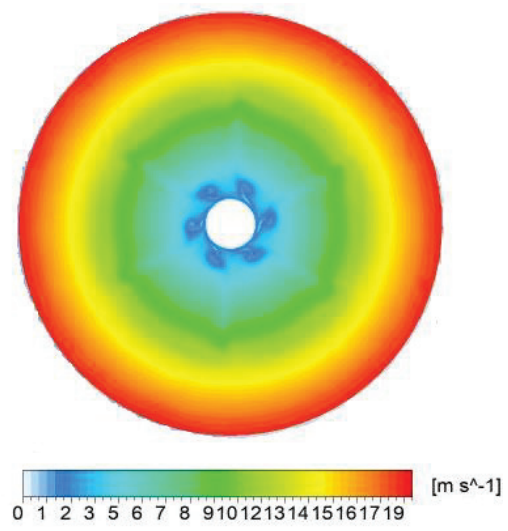

Şekil 5. S7371R Pervanesi J=0.7 için Pervane Gerisi İz Durumu (0.2xR) 


\subsection{BB2 Joubert Denizaltı Modeli Direnç ve Nominal İz Değerlerinin HAD ile Tahmini}

BB2 Joubert denizaltısının model ölçeğinde analizleri yapılırken $5 \times \mathrm{L}$ uzunluğunda ve $3 \times \mathrm{X}$ çapında silindirik bir hacmin içerisine yerleştirilmiştir. Akışın girdiği yüzey silindirde hız girişi olarak tanımlanıp, hız 1.2 m/s olarak girilmiştir, akışın çıkışı basınç çıkışı olarak tanımlanmıştır. Kalan dış yüzey simetri, denizaltı yüzeyi ise duvar olarak tanımlanmıştır (Şekil 6).

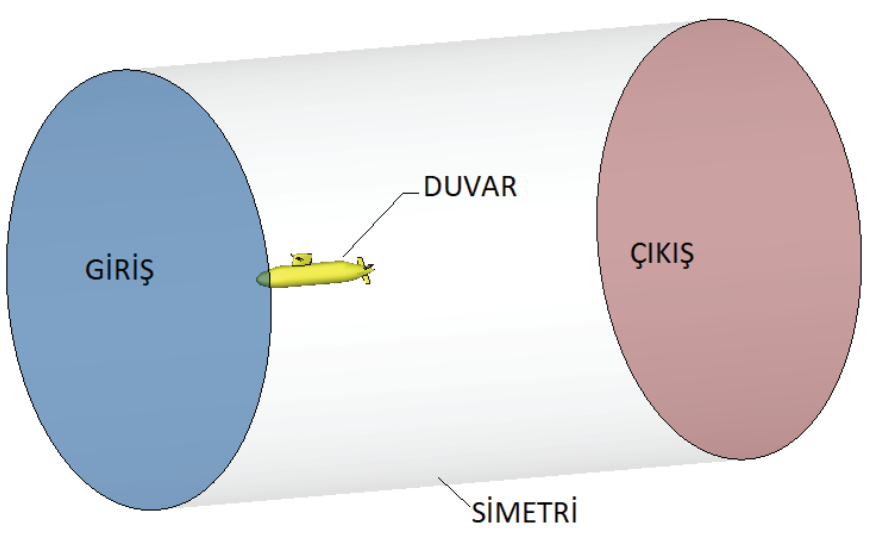

Şekil 6. BB2 Joubert model denizaltısı çözüm ağı

Analiz, sevk noktası hızında, $4.58 \times 10^{6}$ Reynolds sayısında, $\mathrm{y}^{+}=50$ seçilerek yürütülmüştür. Farklı çözüm ağı yoğunluklarına göre model ölçeğinde yapılan analiz sonuçları Tablo 5 'te sunulmuştur.

Tablo 5. HAD ile elde edilen BB2 Joubert denizaltısının direnç değerleri

\begin{tabular}{|l|c|c|}
\hline \multirow{2}{*}{ Hız $1.2 \mathrm{~m} / \mathrm{s}$} & Hacim Hücre & CFD Analiz Değerleri (N) \\
\cline { 3 - 3 } & Sayısı & Model Ölçek \\
\hline Seyrek Ağ Yoğunluğu & $5.7 \times 10^{6}$ & 22.103 \\
\hline Orta Ağ Yoğunluğu & $11.2 \times 10^{6}$ & 21.676 \\
\hline Sık Ağ Yoğunluğu & $22.0 \times 10^{6}$ & 21.581 \\
\hline
\end{tabular}

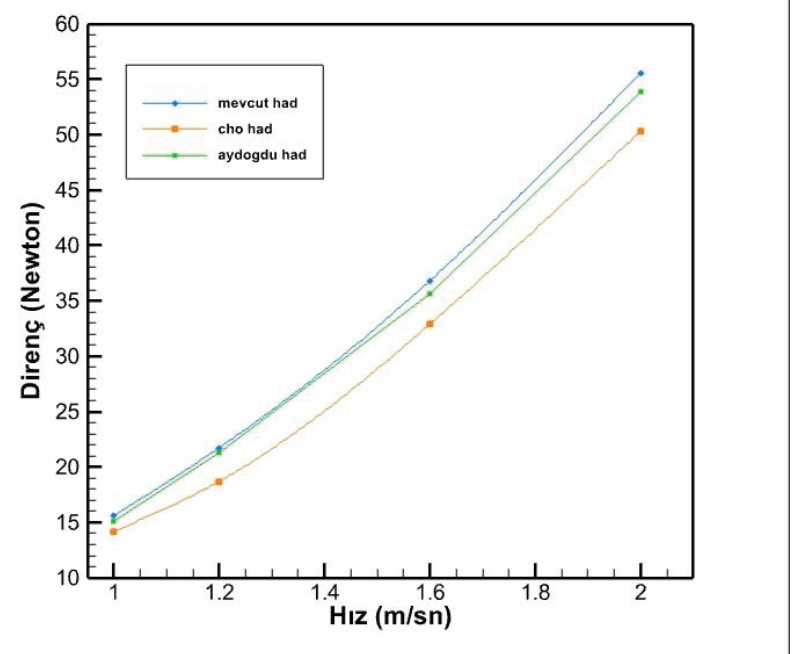

Şekil 7. BB2 Joubert Denizaltı Modelinin direnç değerleri 
Direnç değerleri literatürde bulunan model ölçeğinde yapılan HAD çalışmaları ile karşılaştırılmıştır (Şekil 7). Cho vd. (2020) tarafında sunulan değerlere göre \%12 mertebesinde bir sapma, Aydogdu vd. (2021) tarafından sunulan değerlere göre \%3 mertebesinde bir sapma gözlemlenmiştir.

\subsection{BB2 Joubert Denizaltı Modelinin Sevk Noktasının HAD ile Tahmini}

S7371R pervanesi ile sevk edilen BB2 denizaltııının (Şekil 8) yapılan sevk analizlerinde, pervane ve denizaltı modellerinin analizlerinde kullanılan ağ yoğunlukları kullanılmıştır. Pervane için hata payı en düşük olması sebebi ile sık ağ yoğunluğu, denizaltı için orta ağ yoğunluk özellikleri tercih edilmiştir. Pervane hacmi için $5 \times 10^{6}$ ve denizaltı hacmi için $11.5 \times 10^{6}$ olmak üzere toplamda $16.5 \times 10^{6}$ hücre sayısından oluşan bir çözüm ağı oluşturulmuştur. Ağ görünümü Şekil 10' da verilmiştir. Sevk noktasının bulunması için yapılan analizlerde, denizaltının pervane bölümü 2xD uzunluğunda $1.5 x D$ çapında küçük bir silindir blok ile denizaltı ise, $5 \times \mathrm{L}$ uzunluğunda $3 \times \mathrm{x}$ çapında büyük bir silindirik blok ile çözüm hacmi oluşturulmuştur. Büyük silindirinde akışın girdiği yüzey hız girişi olarak tanımlanıp $1.2 \mathrm{~m} / \mathrm{s}$ olarak girilmiştir, çıktığı yüzey basınç çıkısı olarak tanımlanmıştır. Denizaltı ve pervane yüzeyleri duvar olarak seçilmiştir. Küçük silindirin yüzeyleri ara yüzey, büyük silindirin kabuğu ise simetri olarak tanımlanmıştır (Şekil 9). Pervane dönme hareketi, küçük silindire MRF yöntemi ile uygulanmıştır.

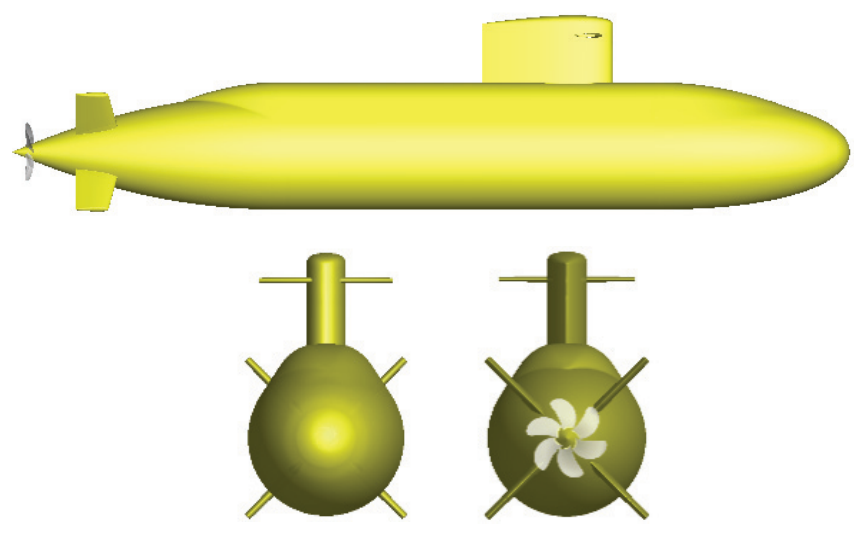

Şekil 8. S7371R pervanesi ile BB2 Joubert denizaltıSı

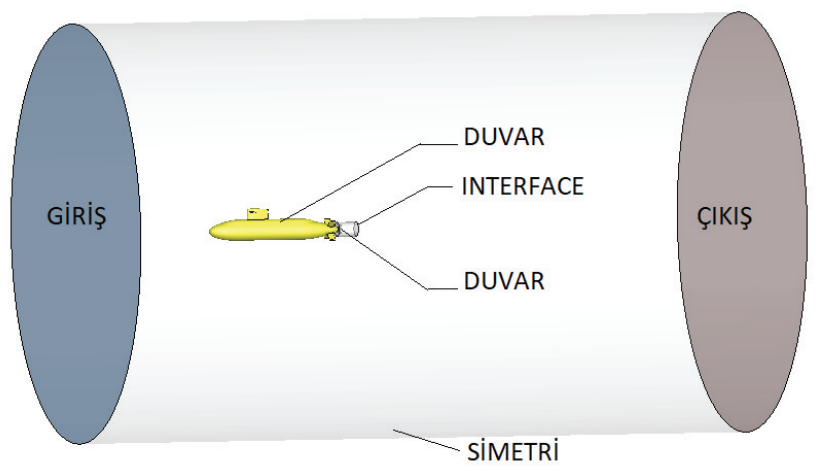

Şekil 9. Pervaneli denizaltı çözüm hacmi görünümü

BB2 Joubert denizaltısının sevk noktasının bulunmasında, değişken yüklü sevk deneyi yöntemi uygulanmıştır (ITTC, 2017). Sabit akış hızında pervane devir sayısı değiştirilerek, pervane itmesinin gemi direncine eşit olduğu nokta belirlenmiştir. Bunun için pervaneli denizaltı modeline akış hızı V=1.2 m/s 
olarak gönderilmiş ve pervane devri farklı pervane yüklemelerine denk gelecek şekilde tahmini sevk noktasından büyük ve küçük olacak şekilde değiştirilmiştir. Her iki durum için elde edilen pervane itmesi ve denizaltı direnci değerlerinin kesişiminden ortaya çıkan devir değeri sevk noktası olarak belirlenerek bu değer için de analiz yapılmıştır (Şekil 11). Böylece sevk noktası 279 rpm olarak elde edilmiştir. Model ölçeği için sevk noktasındaki itme, direnç ve pervane devir sayıları değerleri Tablo $6^{\prime}$ da verilmiştir.

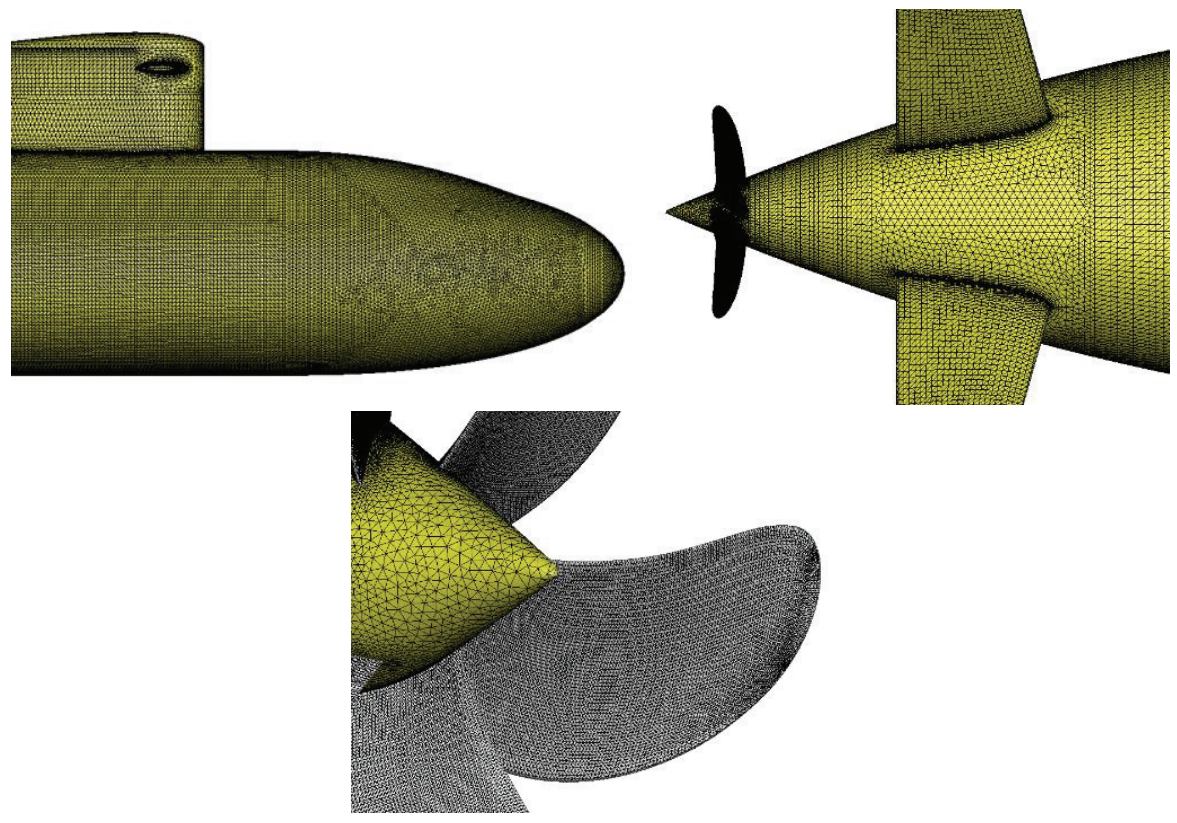

Şekil 10. Pervaneli denizaltı çözüm ağı görünümü

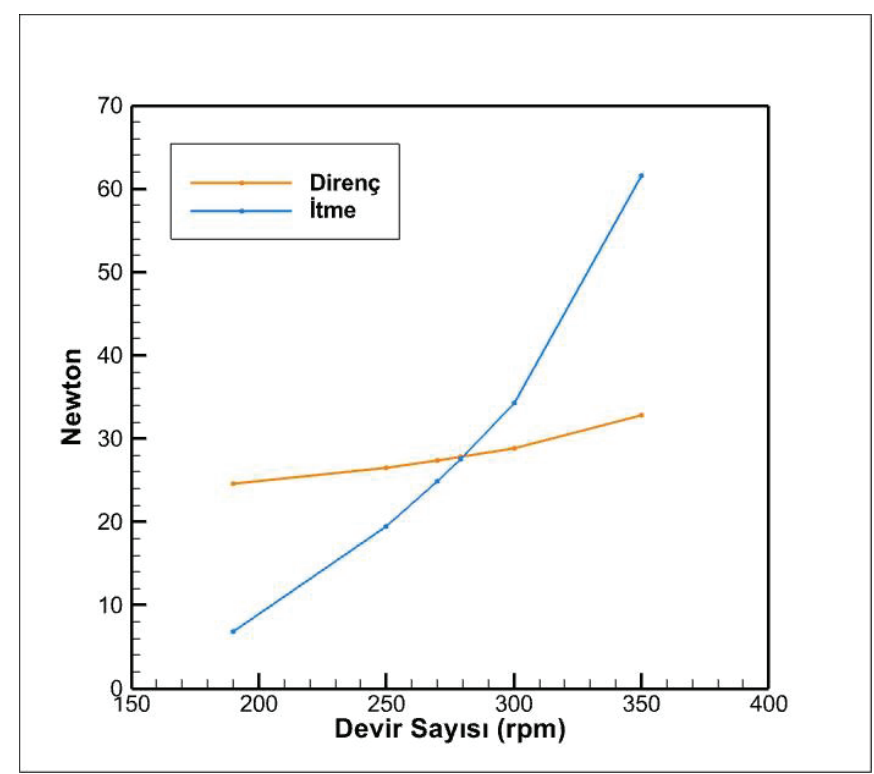

Şekil 11. Sevk noktasının belirlenmesi

Tablo 6. Sevk noktası belirlemek için yapılan analiz sonuçları

\begin{tabular}{|l|c|c|c|c|c|c|}
\hline $\mathrm{n}(\mathrm{rpm})$ & 190 & 250 & 270 & 279 & 300 & 370 \\
\hline $\mathrm{T}(\mathrm{N})=$ & 6.7923 & 19.4907 & 24.8793 & 27.5714 & 34.2976 & 61.5652 \\
\hline $\mathrm{R}(\mathrm{N})=$ & 24.5341 & 26.4908 & 27.3389 & 27.7512 & 28.8438 & 32.7838 \\
\hline
\end{tabular}


$\mathrm{V}=1.2 \mathrm{~m} / \mathrm{s}$ hızı için sevk noktasında pervane devri $\mathrm{n}=279 \mathrm{rpm}$ olarak hesaplanmıştır. Bu değerler için sevk noktasındaki ilerleme hızı $\mathrm{J}_{\mathrm{P}}=0.945$ olarak belirlenmiştir. Aynı devir için itme değeri $\mathrm{T}=27.5714 \mathrm{~N}$ olup moment değeri $Q=1.33 \mathrm{Nm}$ 'dir. Buradan pervanenin $\mathrm{K}_{\mathrm{TM}}$ ve $\mathrm{K}_{\mathrm{QM}}$ değerleri aşağıdaki gibi elde edilir.

$$
\begin{aligned}
& \mathrm{K}_{\mathrm{TM}}=\frac{\mathrm{T}}{\rho * \mathrm{n}^{2} * \mathrm{D}^{4}}=0.22998 \\
& \mathrm{~K}_{\mathrm{QM}}=\frac{\mathrm{Q}}{\rho * \mathrm{n}^{2} * \mathrm{D}^{5}}=0.04059
\end{aligned}
$$

Pervanenin denizaltı arkasındaki durumda açık su karakteristiğini belirlemek için bu çalışmada itme benzerliği yaklaşımı kullanılmıştır. Bunun için S7371R pervanesi açık su grafiği üzerinde, sevk durumu için elde edilen $\mathrm{K}_{\mathrm{TP}}$ değeri işaretlenmiş ve y eksenine paralel bir dikme çizilmiştir. Bu dikmenin pervane ilerleme katsayısı, tork katsayısı ve verim eğrilerini kestiği noktalar işaretlenip açık su pervane eğrilerinden aşağıdaki gibi okunmuştur (Tablo 7).

Tablo 7. S7371R pervanesinin $\mathrm{K}_{\mathrm{TP}}$ değeri için açık su pervanesinde okunan değerler

\begin{tabular}{|l|l|}
\hline \multicolumn{2}{|l|}{$\mathrm{K}_{\text {TP }}$ değeri için Şekil 4'te okunan değerler } \\
\hline $\mathrm{J}_{\circ}$ & 0.606 \\
\hline $\mathrm{K}_{\mathrm{Q}}$ & 0.061 \\
\hline$\eta_{\mathrm{O}}$ & 0.357 \\
\hline
\end{tabular}

Bu değerler yardımı ile sırasıyla model için Taylor iz katsayısı, itme azalması (Yüzey Sürtünmesi Doğrulaması $\left(F_{D}\right)$ dahil edilmeden), tekne verimi, bağıl dönme verimi ve sevk verimi aşağıdaki gibi hesaplanır.

Taylor iz katsayısı;

$$
\mathrm{w}_{\mathrm{t}}=\frac{\mathrm{JP}_{\mathrm{P}}-\mathrm{J}_{0}}{\mathrm{~J}_{\mathrm{P}}}=0.3588
$$

İtme azalması;

$$
\mathrm{t}=\frac{\mathrm{T}_{M}-\mathrm{R}_{\mathrm{m}}}{\mathrm{T}_{M}}=0.214
$$

formülü ile hesaplanmıştır. Buradan tekne verimi;

$$
\eta_{H}=\frac{1-t}{1-w_{t}}=1.2258
$$

Bağıl dönme verimi;

$$
\eta_{\mathrm{R}}=\frac{\mathrm{K}_{\mathrm{Q} 0}}{\mathrm{~K}_{\mathrm{QP}}}=1.4913
$$

Sevk verimi;

$$
\eta=\eta_{\mathrm{H}} * \eta_{\mathrm{O}} * \eta_{\mathrm{R}}=0.6526
$$

olarak bulunmuştur. 


\section{Tam Ölçek BB2 Denizaltısının Sevk Noktasının Tahmini}

Direnç ve sevk karakteristiklerinin tahmini model ölçeğinde elde edilen HAD verilerinden, ITTC Direnç Testi Prosedürü (ITTC, 2011) ve değişken yüklemeli sevk deneyi yöntemlerine (Thomas, 2003) uygun olacak şekilde tam ölçeğe geçiş yapılarak belirlenmiş ve karşılaştırılmıştır.

\subsection{Tam Ölçekte Direnç Tahmini}

ITTC'nin (ITTC, 2017) prosedürlerine uygun bir şekilde orta yoğunluklu çözüm ağı için model ölçekten gerçek ölçeğe geçilerek tam ölçek için hesaplanan direnç değeri paylaşılmıştır. Model ölçeğin toplam direnç katsayısı ve sürtünme direnci katsayısı Denklem 8 ve Denklem 9'dan elde edilmiştir. Çalışma denizaltı üzerinde gerçekleştirildiği için form faktörü formülündeki dalga direnci katsayısı inmal edilerek, Denklem 11'deki gibi kullanılmıştır. Buradan elde edilen model ölçek form faktörü değeri gerçek ölçek form faktörü değerine eşit kabul edilerek gerçek denizaltının direnci elde edilmiştir.

Modelin toplam direnç katsayısı $\left(\mathrm{C}_{\mathrm{TM}}\right)$,

$$
C_{T M}=\frac{R_{T M}}{\frac{1}{2} \rho_{M} S_{M} V_{M}^{2}}=4.722 \times 10^{-3}
$$

Modelin sürtünme direnç katsayısı $\left(C_{F M}\right)$,

$$
C_{F M}=\frac{0.075}{\left(\log _{10} R e_{M}-2\right)^{2}}=3.536 \times 10^{-3}
$$

Form faktörü katsayısı $\left(k_{M}\right)$,

$$
\left(1+k_{M}\right)=\frac{C_{T M}}{C_{F M}}=1.335
$$

Model-gerçek geçişinde yapılan kabuller,

$$
k_{M}=k_{S}
$$

Gerçek ölçek denizaltı direnci $\left(\mathrm{R}_{\mathrm{TS}}\right)$,

$$
R_{T S}=C_{T S} \frac{1}{2} \rho_{S} S_{S} V_{S}^{2}=87.662 \mathrm{kN}
$$

Burada;

$$
C_{T S}=(1+\mathrm{k}) * C_{F S}+\Delta C_{F}+C_{A}
$$

olarak kullanılmıştır.

\subsection{Tam Ölçekte Sevk Noktasının Sadece Değişken Yüklemeli Sevk Deneyi Yöntemine Göre Tahmini}

ITTC 1978 güç tahmin yöntemi (ITTC, 2017) gemi ve denizaltıların güç tahmininde yaygınlıkla kullanılan bir güç tahmin yöntemidir. ITTC 1978 Yöntemi özellikle pervane gövde etkileşiminin zayıf olduğu durumlarda daha iyi tahminlerde bulunmaktadır. Podlu pervane, nozullü pervane gibi etkileşimin arttığı durumlarda tahminlerde hatalara sebep olabilmektedir. Bu eksikliklerin üstesinden gelmek için, Kracht (1991) ve Schmiechen (1987), yalnızca bir deney setine dayanan değişken yüklemeli sevk deneyi yöntemini önermiş̧ir. Ayrı ayrı pervane açık su deneyi, direnç deneyi ve sevk deneyine ihtiyaç duyan ITTC 1978 Yöntemi'nin aksine değişken yüklemeli sevk deneyi yönteminde sadece pervaneli denizaltının farklı pervane yüklemelerinde yapılan sevk deneyleri verileri kullanılır. Gövde pervane etkileşiminin ölçümü itme azalması katsayısı ile yapılmaktadır. 0.1'den küçük değerler gövde pervane 
etkileşiminin düşük olduğunu gösterirken, 0.3 civarındaki değerler güçlü gövde pervane etkileşimini gösterir (Thomas, 2003).

Değişken yüklemeli sevk deneyi yöntemine göre yapılan güç tahmininde kullanılan ve dalmış durumda bir denizaltının üzerine etkiyen kuvvetler Şekil 12'de gösterilmektedir. Burada, V hızında ilerlemekte olan bir denizaltı için $\mathrm{T}$ : itme, $\mathrm{F}$ : çekme kuvveti, $\mathrm{FT}=0$ : pervane çalışmazken ölçülen direnç ve a: direnç artışıdır.

$$
F=-\left(1-t^{*}\right)+F_{T=0}
$$

Denklem 14 çekme kuvveti-itme denklemi olarak verilmektedir (Şekil 13).

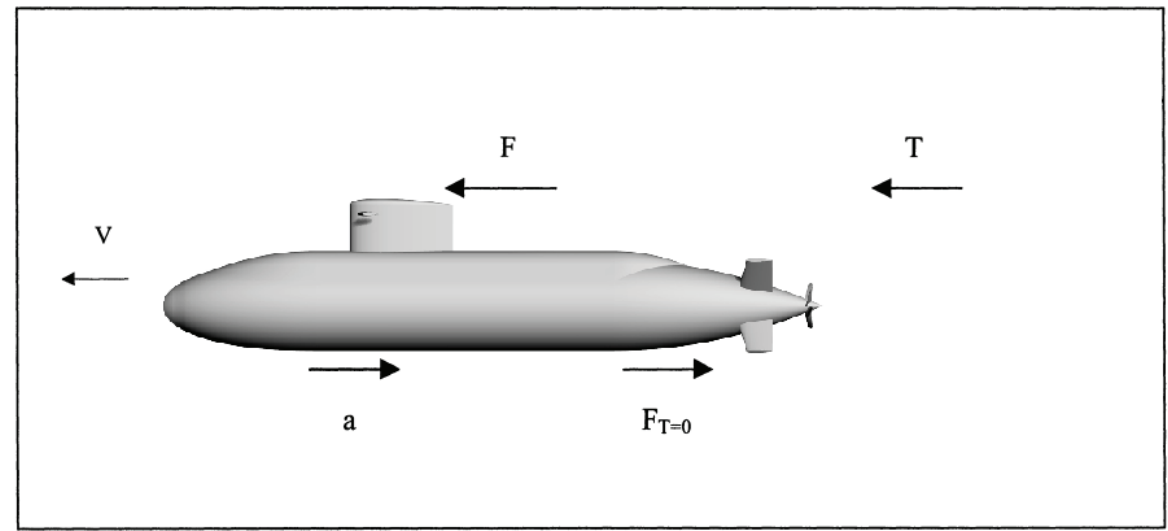

Şekil 12. Dalmış bir denizaltı üzerine etkiyen kuvvetler

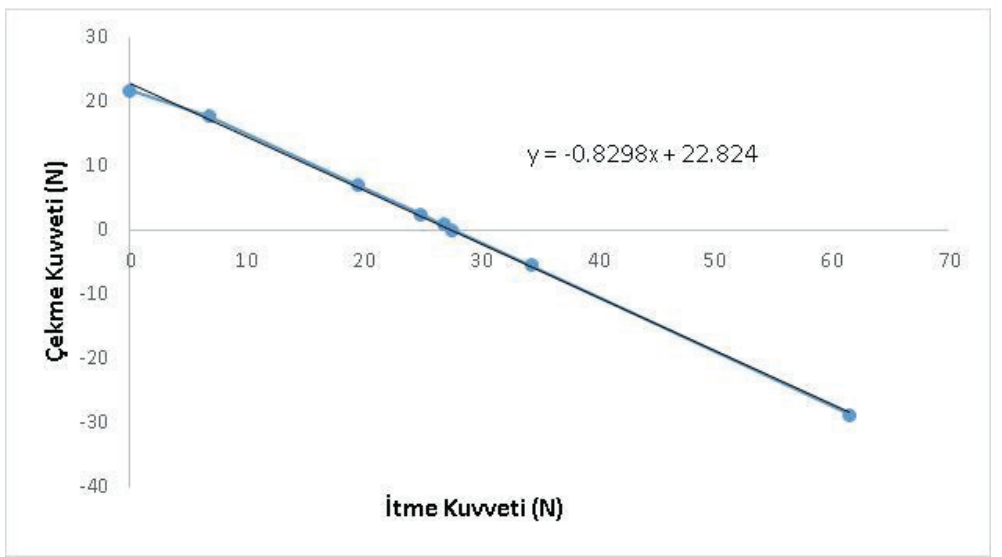

Şekil 13. Çekme kuvveti- İtme kuvveti

Buradan itme azalması,

$$
-(1-t)=\frac{d F}{d T}=-0.8298
$$

olarak hesaplanır.

ITTC 1978'e göre ise;

$$
(1-\mathrm{t})=\frac{\mathrm{T}_{M}+F_{D}-\mathrm{R}_{\mathrm{m}}}{\mathrm{T}_{M}}=0.683
$$

Buradaki $F_{D}$ sürtünme kuvveti düzeltme katsayısı ITTC Sevk Testi kılavuzunda yer aldığı şekilde;

$$
F_{D}=\frac{1}{2} \rho_{\mathrm{M}} \mathrm{V}_{\mathrm{M}}^{2} \mathrm{~S}_{\mathrm{M}}\left[(1+\mathrm{k})\left(\mathrm{C}_{\mathrm{FM}}-\mathrm{C}_{\mathrm{FS}}\right)-\Delta \mathrm{C}_{\mathrm{F}}\right]
$$


Denklem 15 ve Denklem 16' dan görüldüğü üzere itme azalması iki farklı yönteme göre elde edilmiştir. ITTC 1978 yöntemine göre itme azalmasını hesaplayabilmek için hem direnç hem de sevk analizi sonucuna ihtiyaç duyulurken, değişken yüklemeli sevk deneyi yöntemine göre sadece sevk analizi verileri yeterli olmaktadır. Daha önce yapılmış HAD çalışmaları ile karşılaştırıldığında değişken yüklemeli sevk deneyi yönteminin ITTC 1978'e göre daha gerçekçi bir sonuç verdiği görülmektedir (Tablo 8). Değişken yüklemeli sevk deneyi yöntemine göre elde edilen itme azalması değeri daha önceki çalışmalara göre \%6.9 sapma ile daha yüksek bir tahminde bulunurken ITTC 1978 yöntemine göre itme azalması tahmini ise \%11.9 sapma ile daha düşük bir tahmin yapmaktadır.

Denizaltının sevk noktasında model itmesi;

$$
T_{M}^{*}=\frac{F_{T=0}-F_{D}}{1-t}=24.0655(\mathrm{~N})
$$

Denizaltının sevk noktasında denizaltının itmesi;

$$
T_{S}^{*}=T_{M}^{*} \lambda^{3} \rho_{S} / \rho_{M}=152.365(\mathrm{~N})
$$

Olarak hesaplanır. Tam ölçekteki denizaltının sevk karakteristikleri model ölçeğinde elde edilen verilerden sadece değişken yüklemeli sevk deneyi yöntemine göre aşağıdaki şekilde tahmin edilmiş ve literatürde verilen deney ve HAD sonuçları ile karşılaştırılmıştır. Tam ölçek pervane karakteristikleri ölçek etkileri yönünden aşağıdaki şekilde düzeltilmiştir:

$$
\begin{aligned}
& K_{T S}=K_{T M}-\Delta K_{T} \\
& K_{Q S}=K_{Q M}-\Delta K_{Q} \\
& \Delta K_{T}=-\Delta C_{D} \cdot 0.3 \cdot \frac{P}{D} \cdot \frac{c \cdot Z}{D} \\
& \Delta K_{Q}=-\Delta C_{D} \cdot 0.25 \cdot \frac{c \cdot Z}{D}
\end{aligned}
$$

Direnç katsayısındaki değişim;

$$
\Delta C_{D}=C_{D M}-C_{D S}
$$

Ve burada;

$$
\begin{aligned}
& C_{D M}=2\left(1+2 \frac{t}{c}\right)\left[\frac{0.044}{R e_{c o} 1 / 6}-\frac{5}{R e_{c o}^{2 / 3}}\right] \\
& C_{D S}=2\left(1+2 \frac{t}{c}\right)\left[1.89+1.62 \cdot \log \frac{c}{k_{p}}\right]^{-2.5}
\end{aligned}
$$

Tam ölçekteki denizaltının düzeltilmiş iz değeri;

$$
w_{T S=}\left(t+w_{R}\right)+\left(w_{T M}-t-w_{R}\right) \frac{(1+k) C_{F S}+\Delta C_{F}}{(1+k) C_{F M}}
$$

Olarak hesaplanmış ve ilerleme katsayısı;

$$
J_{S}=J_{M} \frac{\left(1-w_{M}\right)}{\left(1-w_{S}\right)}
$$


Formülü ile düzeltilmiştir. Model gerçek denizaltıya göre çok daha düşük bir Reynolds sayısında test edildiğinden model pervaneye gelen akış hızı $\left(V_{A}\right)$ gerçek denizaltıdaki pervaneye gelen akış hızından daha düşüktür. Böylece gerçek denizaltıdaki iz katsayısı model pervanedekine göre daha düşüktür. Bundan dolayı denizaltı sevk noktasındaki model itmesine denk gelen pervane yüklenme katsayısı gerçek gemininkine göre daha yüksek olmaktadır. Bu model pervane veriminin gerçek geminin arkasındaki pervanenin veriminden daha düşük olmasına neden olur. Bu etkiyi düzeltmek için tam ölçek için ilerleme katsayısı denklem 28'deki gibi düzeltilir (Thomas, 2003). Buradan $\mathrm{K}_{\mathrm{TS}}$, $\mathrm{K}_{\mathrm{Q}}$ se $\mathrm{J}_{\mathrm{S}}$ çizdirilmiş ve $\mathrm{J}_{\mathrm{S}}{ }^{2}$ nin fonksiyonu olacak şekilde ek bir $\mathrm{K}_{\mathrm{TS}}$ eğrisi daha eklenmiştir. Burada;

$$
K_{T S}=\frac{T_{S}^{*}}{\rho_{S} D_{S}^{2} V_{S}^{2}} J_{S}^{2}
$$

İki KTs eğrisinin kesişimi denizaltının tam ölçekteki sevk noktasını vermektedir (Şekil 14). Bu noktadan ölçülen okunan $\mathrm{K}_{\mathrm{TS}}$ ve $\mathrm{J}_{\mathrm{S}}$ değerleri tam ölçek için sevk karakteristiklerinin hesabında kullanılmaktadır. Bunlar;

$$
\begin{aligned}
& n_{S}=\frac{V_{S}}{J_{S} D_{S}} \\
& Q=\rho_{S} n_{S}^{2} D_{S}^{5} K_{Q S}
\end{aligned}
$$

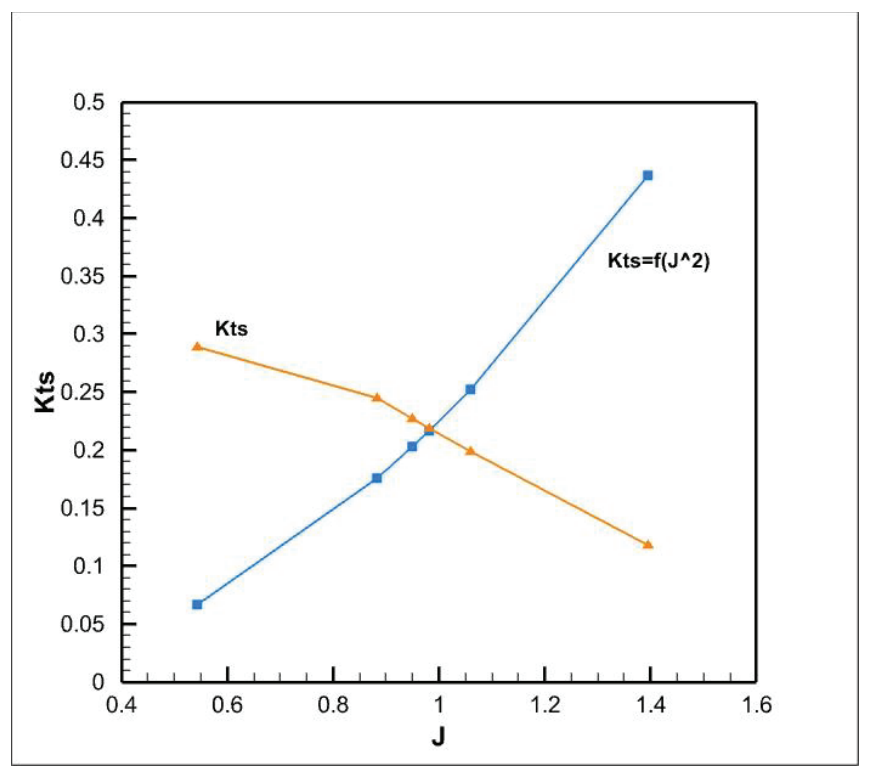

Şekil 14. Tam ölçekte denizaltının sevk noktası

\section{Sonuçlar}

Özellikle askerî açıdan stratejik önemi olan denizaltıların hidrodinamik formunun ve sevk veriminin denizaltıların seyir süresi oranında önemli bir etkisi mevcuttur. Belirli bir hız ve enerji kapasitesi ile daha uzun seyir süresi için daha verimli form tasarımları önem kazanmaktadır. Tasarlanan formların ve pervanelerinin sevk karakteristiklerinin belirlenmesinde hesaplamalı akışkanlar dinamiği yöntemleri günümüzde yaygın olarak kullanılan etkili bir yöntemdir.

Bu çalışmada, S7371R denizaltı pervanesi ile sevk edilen Joubert BB2 denizaltısının model ölçeğindeki direnci ve sevk karakteristikleri hesaplamalı akışkanlar dinamiği yöntemleri ile hesaplanmıştır. Sevk noktasının tayini ile denizaltı formuna has Taylor iz katsayısı, itme azalması, tekne verimi, bağıl dönme 
verimi ve bunlara bağlı sevk verimi ifadeleri hesap edilmiştir. Hesaplamalarda RANS denklemleri zamandan bağımsız şekilde k-w SST viskoz akış modeli ve 16.5 milyonluk ağ yoğunluğu ile çözülmüş denizaltı direnci, pervane açık su karakteristikleri ve sevk karakteristikleri elde edilmiştir. Daha sonra model ölçeğinden tam ölçeğe değişken yüklemeli sevk deneyi yöntemi kullanılarak geçilmiş ve literatürde verilen değerler ile karşılaştırılmıştır.

Elde edilen değerlerin daha önce literatüre sunulmuş deneysel değerler ve HAD sonuçları ile uyum içinde olduğu görülmüştür. Tablo 8'de bu çalışmada hesaplanan değerlerin, Carrica vd. (2016)'da elde edilen deney sonuçları ve HAD sonuçlarına göre sapma miktarları verilmiştir. Değerlerin sevk noktasındaki pervane devri için deneye göre \%0.3, HAD’ne göre \% 3 sapma miktarı ile elde edildiği görülmektedir. İtme azalması ise \%6,9 sapma miktarı ile yakın bir değer bulunmuştur. İtme değeri deney ve HAD'ye göre sırası ile \%5.7 ve \%1.3 hatalı olarak bulunmuştur. Tork değeri deney ve HAD'ye göre sırası ile \%5.4 ve \%5.4 hatalı olarak bulunmuştur. Daha önce literatüre sunulan deney ve HAD sonuçları ile olan karşılaştırmadan sadece değişken yüklemeli sevk deneyi yöntemi kullanılarak tam ölçek için denizaltının sevk performansının yüksek mertebede bir doğruluk ile tahmin edilebildiği görülmektedir. Daha sonraki çalışmalarda farkı tahmin yöntemleri kullanılarak tam ölçeğe geçilmesi planlanmaktadır.

Tablo 8. S7371R pervaneli BB2 denizaltısının sevk noktasının literatür ile karşılaştırılması

\begin{tabular}{|c|c|c|c|c|c|c|c|}
\hline & \multicolumn{5}{|c|}{ Kendi Kendini İtme Notası } & \multicolumn{2}{|c|}{ Sapma Miktarı (\%) } \\
\hline & $\begin{array}{c}\text { Deney } \\
\text { (Carrica } \\
\text { vd. 2016) }\end{array}$ & $\begin{array}{c}\text { HAD } \\
1 \\
\text { (Carrica } \\
\text { vd. } \\
2016)\end{array}$ & $\begin{array}{c}\text { HAD } \\
2 \\
\text { (Carrica } \\
\text { vd. 2016) }\end{array}$ & $\begin{array}{c}\text { HAD } \\
3 \\
\text { (Carrica } \\
\text { vd. } \\
2016)\end{array}$ & $\begin{array}{c}\text { HAD } \\
\text { (Mevcut } \\
\text { Çalışma) }\end{array}$ & Deneye göre & $\begin{array}{l}\text { HAD 1'e } \\
\text { göre }\end{array}$ \\
\hline İtme $\left(T_{s}\right)$ & 161.5 & 154.4 & 157.2 & 156.3 & 152.4 & 5.7 & 1.3 \\
\hline Tork (Qs) & 130.6 & 130.7 & 131.2 & 136.8 & 137.7 & 5.4 & 5.4 \\
\hline $\begin{array}{l}\text { İtme Katsayısı } \\
\left(\mathrm{K}_{\mathrm{T}}\right)\end{array}$ & 0.228 & 0.234 & 0.219 & 0.215 & 0.227 & 0.4 & 2.9 \\
\hline $\begin{array}{l}\text { Tork Katsayısı } \\
\left(\mathrm{K}_{\mathrm{Q}}\right)\end{array}$ & 0.369 & 0.387 & 0.366 & 0.370 & 0.390 & 5.7 & 0.7 \\
\hline $\begin{array}{l}\text { İtme azalması } \\
(1-t)\end{array}$ & - & 0.776 & 0.765 & - & 0.829 & - & 6.9 \\
\hline $\begin{array}{l}\text { Pervane devri } \\
\text { (rpm) }\end{array}$ & 63.1 & 61 & 63.5 & 64.2 & 62.9 & 0.3 & 3 \\
\hline
\end{tabular}

\section{Referanslar}

Groves, N.C., Huang T.T., ve Chang, M.S., "Geometric Characteristics of DARPA Suboff Models", David Taylor Research Center, Ship Hydromechanics Department, Report Number DTRC/SHD-1298-01, 1989.

Huang T., Liu H. ve Groves N., "Experiments of DARPA Suboff Program", David Taylor Research Center, Ship Hydromechanics Department, Report Number DTRC/SHD-1298-02, 1989.

Crook, L.B., "Resistance for DARPA Suboff as Represented by Model 5470", DTRC/SHD-1298-07, 1990. 
Roddy, R.F., "Investigation of the Stability and Control Characteristics of Several Configurations of the DARPA Suboff Model (DTRC 5470) from Captive-Model Experiments, DTRC/SHD-1298-08, 1990.

Liu, H. ve Huang T., "Summary of DARPA Suboff experimental program data", Report NumberCRDKNSWC/HD-1298-11, 1998.

Di Fellice F., Felli M., Liefvendahl M. ve Svennberg U., "Numerical and Experimental Analysis of the wake behavior of a Generic Submarine Propeller", First International Symposium on Marine Propulsors, Trodheim, Norway, 2009.

Alin, N., Bensow, R., Fureby, C. ve Huuva, T., "Current Capabilities of DES and LES for Submarines at Straight Course", Journal of Ship Research, Vol. 54 ,s.184-196, 2010.

Alin, C., Chapius, M., Fureby, C., Liefvendahl, M., Svennberg, U. ve Troeng, C., "A Numerical Study of Submarine Propeller- Hull Interactions", 28th Symposium on Naval Hydrodynamics, Pasadena, A.B.D., 2010

Liefvendahl, M., Troeng, C., "Computation of Cycle-to-cycle Variation ib Blade Load for a Submarine Propeller using LES", Second International Symposium on Marine Propulsors, Hamburg, 2011.

N. Chase and P. M. Carrica, "Submarine propeller computations and application to self-propulsion of DARPA Suboff," Ocean Eng., vol. 60, pp. 68-80, 2013, doi: 10.1016/j.oceaneng.2012.12.029.

Ozden M. C. , Gurkan A. Y. , Ozden Y. , Canyurt T. G. , Korkut E., " Underwater radiated noise prediction for a submarine propeller in different flow conditions", Ocean Engineering, cilt.126, ss.488-500, 2016.

A. Özden, Y., Çelik, F., " Denizaltı Kıç Koniklik Açısının Ve Boy-Genişlik Oranının Tekne Verimi Üzerine Etkilerinin Sayısal Olarak İncelenmesi", Gemi ve Deniz Teknolojisi, sa.208, ss.71-87, 2017.

S. Sezen, A. Dogrul, C. Delen, and S. Bal, "Investigation of self-propulsion of DARPA Suboff by RANS method," Ocean Eng., vol. 150, no. July 2017, pp. 258-271, 2018, doi: 10.1016/j.oceaneng.2017.12.051.

O. K. Kinaci, M. K. Gokce, A. D. Alkan, and A. Kukner, "On self-propulsion assessment of marine vehicles," Brodogradnja, vol. 69, no. 4, pp. 29-51, 2018, doi: 10.21278/brod69403.

A. Özden Y. , Özden M. C. , Demir E., Kurdoğlu S., "Experimental and Numerical Investigation of DARPA Suboff Submarine propelled with INSEAN E1619 Propeller for Self-Propulsion", Journal Of Ship Research, cilt.63, sayı 4, ss.235-250, 2019.

Sezen, S., Delen, C., Dogrul, A., Atlar, M., "An investigation of scale effects on the self-propulsion characteristics of a submarine", Applied Ocean Research 113, 2021, doi:10.1016/j.apor.2021.102728.

Joubert, P.N., "Some Aspects of Submarine Design Part 1", Australia Defence Science and Technology Organisation Report DSTO-TR-1622, 2004.

Joubert, P.N., "Some Aspects of Submarine Design Part 2", Australia Defence Science and Technology Organisation Report DSTO-TR-1920, 2006.

Quick, H. ve Woodyatt, B., "Experimental Testing of a Generic Submarine Model in the DSTO Low Speed Wind Tunnel", Defence Science and Technology Organisation, DSTO-TN-1274, Mart 2014.

Toxopeus, S.I., "SHWG Collaborative Exercise: BB1", MARIN Report No. 24784-3-RD, Ekim 2013. 
Toxopeus, S.I. Quadvlieg, F. ve Kerkvliet, M., "SHWG Collaborative Exercise: Part 6: Generic Submarine Hydrodynamics BB2, MARIN İnformal document", Eylül 2017.

P. M. Carrica, M. Kerkvliet, F. Quadvlieg, and J. E. Martin, "CFD Simulations and Experiments of a Maneuvering Generic Submarine and Prognosis for Simulation of Near Surface Operation," 31st Symp. Nav. Hydrodyn. (ONR), Monterey, CA, no. September, pp. 11-16, 2016.

P. M. Carrica, Y. Kim, and J. E. Martin, "Near-surface self propulsion of a generic submarine in calm water and waves," Ocean Eng., vol. 183, no. May, pp. 87-105, 2019, doi: 10.1016/j.oceaneng.2019.04.082.

R. Skejic and M. Greve, "On the Added Resistance of Underwater Vehicles in Close Proximity to Regular Waves" Conference: Warship 2017: Naval Submarines \& UUVsAt: Bath, UK, June 2017.

B. Overpelt, B. Nienhuis, and B. Anderson, "Free Running Manoeuvring Model Tests On A Modern Generic SSK Class Submarine (BB2)," Pacific Int. Marit. Conf., 2015.

M. Pontarelli, J. E. Martin, and P. M. Carrica, "Dynamic Instabilities in Propeller Crashback," Proc. Fifth Int. Symp. Mar. Propulsors, vol. 1, no. June, 2017.

Y. J. Cho, W. Seok, K. H. Cheon, and S. H. Rhee, "Maneuvering simulation of an X-plane submarine using computational fluid dynamics," Int. J. Nav. Archit. Ocean Eng., vol. 12, pp. 843-855, 2020, doi: 10.1016/j.ijnaoe.2020.10.001.

B. Aydogdu, A. Dogrul, and F. Cakici, "Resistance Analyses Of Joubert BB2 Benchmark,"2nd international congress on ship and marine technology (GMO- SHIPMAR 2021), pp. 1-10, Istanbul 2021.

ITTC, "Recommended Procedures and Guidelines, Propulsion/Bollard Pull Test", Revision 05, 7.5 - 02, 03 - 01.1, 2017.

ITTC, "Recommended Procedures and Guidelines, Resistance Test", Revision 03, 7.5 - 03, 02 - 03, 2011.

Thomas, R., "Performance Evaluation of the Propulsion System for the Autonomous Underwater Vehicle C-Scout", Master Thesis, Memorial University of Newfoundland, Ağustos 2003.

ITTC, "1978 ITTC Performance Prediction Method", 7.5-02-03-01.4, 2017.

Schmiechen M., "Wake and Thrust Deduction from Quasisteady Ship Model Propulsion Tests Alone", VWS Report no. 1100/87, 1987, Almanya.

Kracht, A.M., "Load Variation Tests Improve the Reliability of Ship Power Predictions Based on Model Test Results", Schiffstechnik 38, 1991, Almanya. 